\title{
PERSPECTIVA DOS ALUNOS DE UM CURSO SUPERIOR SOBRE O USO DAS FERRAMENTAS E-MAIL, CHAT E FÓRUM EM UM AMBIENTE VIRTUAL DE APRENDIZAGEM
}

\author{
Luciana Guimarães Rodrigues de LIMA $^{1}$ \\ Cristina Jasbinschek HAGUENAUER ${ }^{2}$
}

RESUMO: Neste artigo, são apresentados os resultados de uma pesquisa intitulada "Comunicação, Interação e Discurso em Ambientes Virtuais de Aprendizagem", desenvolvida junto ao Programa Interdisciplinar de Linguística Aplicada da Universidade Federal do Rio de Janeiro. O trabalho buscou investigar as possibilidades oferecidas pelas novas tecnologias da informação e foi desenvolvido com base em dados coletados por meio de questionários, entrevistas e observação do ambiente virtual de aprendizagem. A análise privilegiou os momentos de comunicação entre os agentes na Sala Online do Portal Espaço GD, a exemplo dos diálogos que acontecem nas ferramentas e-mail, chat e fórum. Os comentários feitos por meio de questionários e espontaneamente pelos alunos nos registros de e-mails, chats e fóruns foram analisados de modo a identificar núcleos de significado relacionados à percepção dos alunos sobre o ambiente virtual de aprendizagem (AVA).

PALAVRAS-CHAVE: Ambientes virtuais de aprendizagem. Análise do discurso. Educação semipresencial.

\section{Introdução}

Considerando que a Web 2.0 é uma tendência que reforça o conceito de colaboração e de troca de informações entre os internautas, o ambiente online se torna mais dinâmico e colaborativo, o que interfere significativamente na forma de se pensar a educação. Com isso, percebe-se que as práticas pedagógicas não devem se limitar mais ao recebimento passivo de informações, típico das aulas tradicionais.

Nesse sentido, surgem novas formas de comunicação e interação entre professores e alunos, com a utilização de ambientes virtuais de aprendizagem (AVAs), pois apresentam uma proposta para estimular o trabalho cooperativo, a comunicação entre os usuários e a autoria na web, bem como auxiliar a administração do tempo na realização das atividades, uma vez que estas podem ser realizadas fora dos horários previstos pelas aulas presenciais e incentivar a autonomia na busca e seleção de informações. A utilização desses recursos permite introduzir novas práticas de ensinoaprendizagem, possibilitando expandir as experiências dos estudantes. Além disso, os

\footnotetext{
${ }^{1}$ Doutora em Linguística Aplicada. UFRJ - Universidade Federal do Rio de Janeiro. Rio de Janeiro - RJ - Brasil.21941-901 - lucianagrlima@globo.com

${ }^{2}$ Doutora em Engenharia Civil. UFRJ - Universidade Federal do Rio de Janeiro. Escola de Comunicação. Rio de Janeiro - RJ - Brasil. 22290-240 - cristina.haguenauer@ gmail.com
} 
recursos de um ambiente virtual de aprendizagem podem ser utilizados em qualquer disciplina, desde que o professor leve em consideração o perfil e as necessidades dos alunos para planejar seu curso.

\section{Os recursos de comunicação em AVAs: as ferramentas e-mail, chat e fórum}

Estudos como os de Marcuschi (2005) e Belloni (1999) destacam que, atualmente, as ferramentas da Internet mais usadas no contexto educacional são os $e$ mails, os chats, as listas de discussão, o Weblog e a videoconferência. Isso se deve ao fato de que elas apresentam grandes vantagens ao permitirem combinar a flexibilidade da interação humana com a independência no tempo e no espaço, sem por isso perder a velocidade.

Paiva (2004) seleciona algumas considerações sobre o uso do e-mail, como a velocidade na transmissão; a assincronia; o baixo curso; a forma de como uma mensagem pode ser enviada para milhares de pessoas; pode-se facilmente entrar em contato com o usuário; podem ser anexados arquivos em formatos diversos e a mensagem pode ser arquivada, impressa, reencaminhada e copiada. Da mesma forma, Marcuschi (2005) afirma que o e-mail, além de criar possibilidades de estabelecer diálogos com rapidez e objetividade, tem outra característica curiosa quanto à forma de envio: de um para um (de um emissor para um receptor) e de um para vários (de um emissor para vários receptores).

Contudo, Paiva (2004), apresenta algumas desvantagens do e-mail, como por exemplo: a invasão de privacidade, a ansiedade por feedback imediato, gerando uma grande pressão no leitor; a dependência de provedoras de acesso; o excesso de mensagens irrelevantes e indesejadas; problemas de incompatibilidade de software poderem dificultar ou impedir a leitura; o e-mail poder ir para o endereço errado, ser copiado ou alterado; o receptor poder ser involuntariamente incluído em fóruns e malas diretas.

Nesse sentido, Primo (2000) destaca que, mesmo que os e-mails possam ser escritos em HTML, conter imagens ou backgrounds e carregar consigo qualquer outro arquivo (em attachment), certas mensagens não verbais, como fisionomia ou entonação de voz, importantes em um contato interpessoal, não podem ser valorizadas por meio dessa ferramenta. Por consequência, convencionou-se o uso de emoticons com o intuito de oferecer pistas sobre como se sente o redator ao escrever a mensagem. 
O chat é um recurso de comunicação síncrono, isto é, em tempo real, em que os participantes recebem mensagens no momento em que alguém as enviou e viceversa. Para ser realizado, é necessário determinar horários e o número de participantes, além de um mediador para organizar as perguntas, as respostas e os comentários. Segundo Primo (2000), o chat é uma das ferramentas mais poderosas para a interação, pois, devido à velocidade de intercâmbio de mensagens textuais, oferece um palco para diálogos de alta intensidade e para a aproximação de interagentes sem qualquer proximidade física. Tem como característica facilitar a comunicação online entre todos os interlocutores que fazem parte de um grupo e que estejam conectados na Internet.

Para Marcuschi (2005), são denominados chats educacionais aqueles que apresentam as seguintes características:

- os usuários se conhecem ou são identificados por seus nomes;

- o acesso é limitado aos alunos;

- não é hábito usar apelidos;

- o anonimato não é bem-vindo;

- sua intencionalidade está relacionada a conteúdos que dizem respeito ao grupo participante;

- podem funcionar como plantão de dúvidas e/ou aconselhamento;

- por definição, há a figura do professor ou tutor, e os demais participantes são classifícados como alunos.

Já Vaz (2009) sustenta que o fórum é um recurso didático que incentiva a discussão e o aprofundamento de aspectos relacionados aos tópicos abordados e permite registrar experiências. A atividade central desse recurso é alimentada por um debate sobre um determinado tema. Além disso, a elaboração da redação pode ser feita com cuidado, bem estruturada, podendo passar por uma revisão antes de ser enviada. Um aspecto importante do fórum está na criatividade das produções escritas por parte dos seus membros (COSTA et al., 2006). Dessa maneira, o fórum de discussão estabelece um meio de comunicação entre indivíduos, uma comunicação existente entre o processo de formação do conhecimento e a aprendizagem colaborativa, uma forma de cooperação entre os indivíduos participantes.

Vale ressaltar, também, que o fórum é um espaço de compartilhamento em que todos podem ter voz e manifestar-se livremente, promovendo uma discussão que pode ampliar e modificar as informações do curso. Por outro lado, também, é importante para aprofundar uma discussão iniciada em aula presencial e também como instrumento de avaliação. 


\section{Metodologia}

A metodologia adotada na pesquisa (LIMA, 2009) foi a da pesquisa-ação críticocolaborativa proposta por Pimenta (2005), pois procurou investigar uma realidade em seu contexto, ao mesmo tempo em que procurou compreender e intervir na prática docente. Para Thiollent (1994, p.53), na pesquisa-ação, “[...] os problemas colocados são inicialmente de ordem prática. Trata-se de procurar soluções para se alcançar um objetivo ou realizar uma possível transformação dentro da situação observada." Para Franco (2005), a pesquisa-ação crítica considera a voz do sujeito, sua perspectiva e seu sentido não apenas para registro e posterior interpretação do pesquisador, mas se organiza pelas situações relevantes que emergem do processo.

No caso em estudo, a escolha deve-se ao fato de que tal metodologia permite um tipo de investigação muito próxima da prática, inserida no contexto de pesquisa, além de envolver o pesquisador como participante ativo e permitir que as vozes dos membros da realidade pesquisada sejam ouvidas.

Investigar a visão dos alunos nessa instituição de ensino por meio da participação em e-mails, chats e fóruns de discussão online e os fatores que influenciam tal participação foi o desafio desta pesquisa, desenvolvida junto ao Programa Interdisciplinar de Linguística Aplicada da Faculdade de Letras da UFRJ.

A pesquisa foi realizada ao longo de quatro semestres letivos, tendo como público-alvo alunos da disciplina Geometria Descritiva, oferecida na modalidade presencial e complementada pelo suporte online de um ambiente virtual de aprendizagem - a Sala de Aula Online do Portal Espaço GD (LIMA, 2009). Ao todo, foi registrada uma média de 250 alunos do primeiro e segundo períodos dos cursos de Cenografia, Indumentária, Composição de Interiores, Composição Paisagística, Escultura e Licenciatura em Educação Artística - Habilitação em Desenho.

Durante toda a pesquisa foi realizada a análise do conteúdo dos e-mails enviados, das discussões nos fóruns e do histórico dos chats realizados. Os dados foram coletados por meio de questionários e observação do ambiente virtual de aprendizagem. A análise dos dados privilegiou os momentos de comunicação entre os agentes na Sala Online do Portal Espaço GD, a partir das interações que ocorreram no AVA, nas ferramentas e-mail, chat e fórum. Os comentários feitos por meio de questionários e espontaneamente pelos alunos foram analisados de modo a identificar núcleos de significado relacionados à percepção dos alunos sobre o AVA. 
O AVA em estudo foi desenvolvido a partir do Sistema Quantum de Educação Online, fruto de parceria entre a Empresa Semear, o Laboratório de Pesquisa em Tecnologias da Informação e da Comunicação, da Escola de Comunicação da UFRJ (LATEC/ECO/UFRJ) e o Grupo de Representação Gráfica em Ambientes Virtuais, da Escola de Belas Artes da UFRJ (GERGAV/EBA/UFRJ). O sistema foi utilizado como base para desenvolver a plataforma do Centro de Educação Superior a Distância do Estado do Rio de Janeiro (CEDERJ), formado pelo consórcio das universidades públicas do Estado do Rio de Janeiro, do qual a UFRJ participa.

A figura 1 mostra a interface do AVA, dividida em três colunas: na primeira coluna, à esquerda, situam-se as ferramentas do sistema, como Secretaria, Administração, Sala de Aula e Encerrar a Seção. Na coluna central podem ser visualizados, por exemplo, os dados do último acesso ao aluno e as atividades por fazer. A terceira coluna apresenta as ferramentas de interação e consulta disponibilizadas no AVA.

Figura 1 - Interface do AVA Quantum

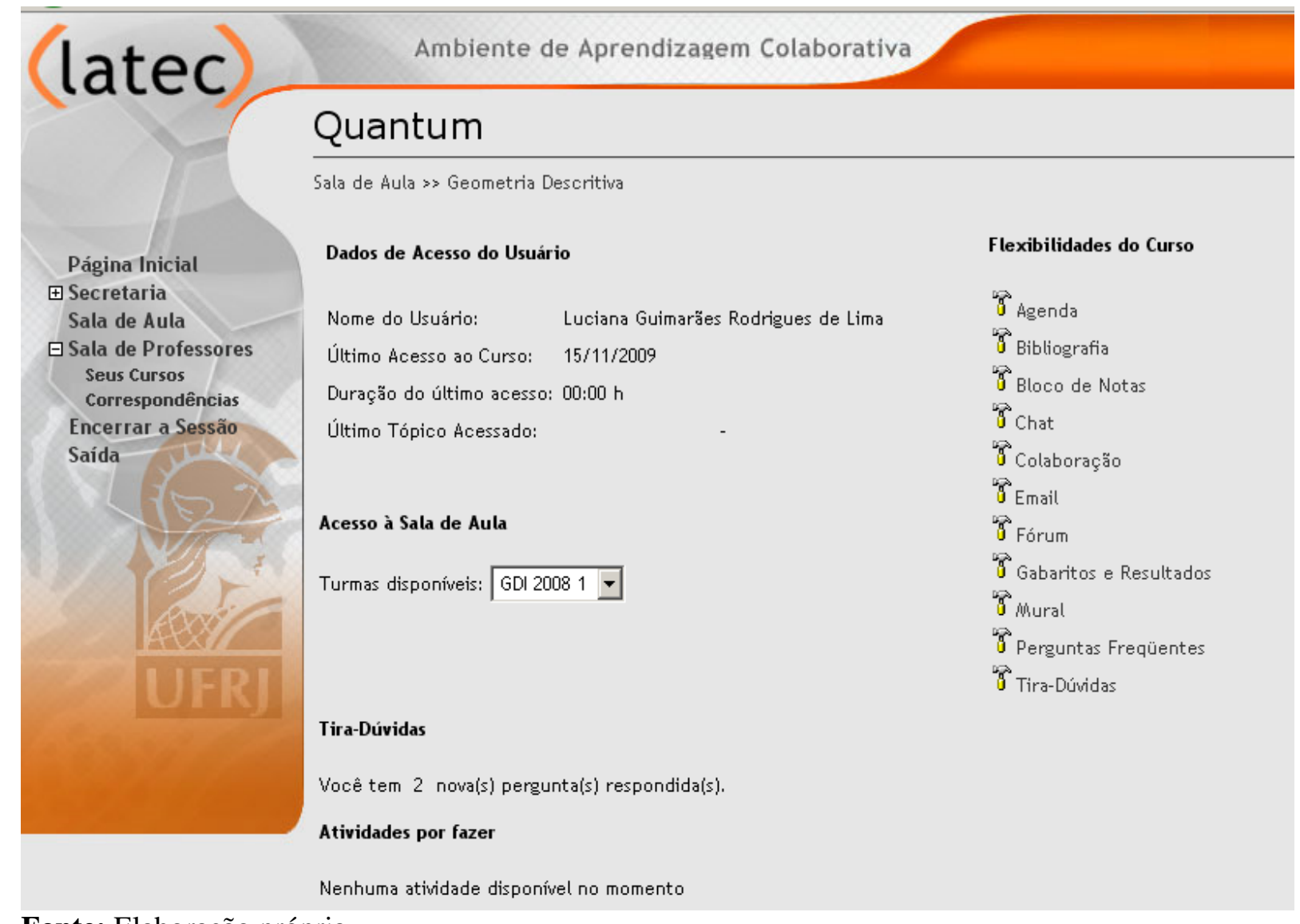

Fonte: Elaboração própria. 


\section{Potencialidades e limitações das ferramentas}

Por acreditar que a maior parte dos alunos já estivesse razoavelmente familiarizada com o ambiente digital, durante a pesquisa optou-se por gerar dados usando a própria Sala de Aula Online e identificar a percepção por meio da manifestação espontânea do conteúdo nos canais de comunicação (e-mail, chat e fórum).

\section{E-mail}

A figura 2 apresenta a interface da ferramenta $e$-mail, onde se podem observar as facilidades oferecidas, como a lista de usuários (à esquerda) e a lista de destinatários (no centro da tela). À direita da tela, pode-se observar o menu de seleção de ferramentas, que permanece visível para facilitar o processo de navegação.

Figura 2 - Interface da ferramenta $e$-mail

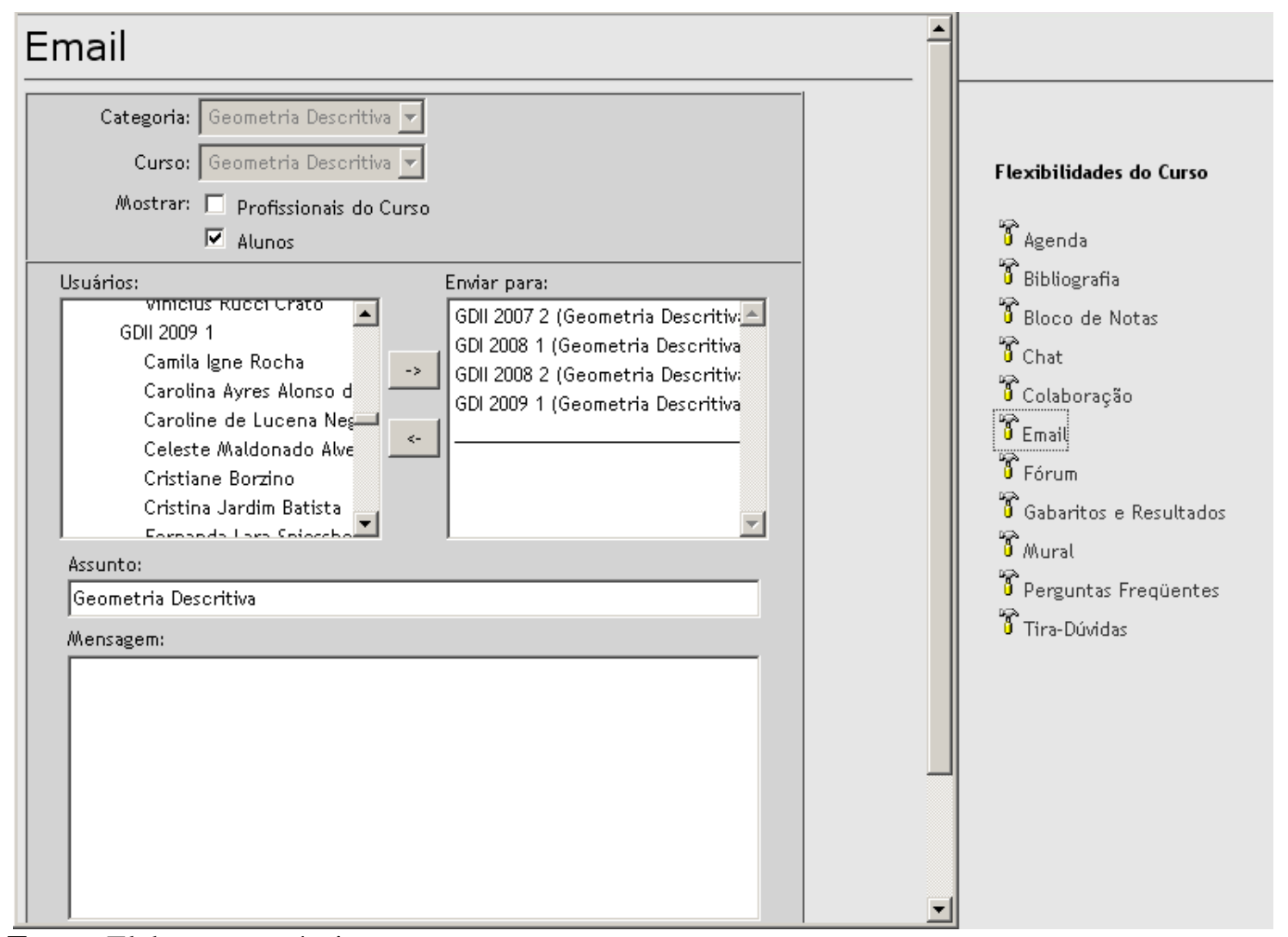

Fonte: Elaboração própria.

A ferramenta e-mail foi imprescindível para a comunicação entre professor e alunos. O professor conseguia enviar a mesma mensagem para todos os alunos da mesma turma ou para todas as turmas registradas no AVA. Além disso, os alunos 
puderam se comunicar entre si de forma mais prática, pois os e-mails dos colegas estavam registrados no sistema.

Nos relatos a seguir, feitos por alunos e registrados das conversas no chat, serão apresentadas as potencialidades e limitações dessa ferramenta.

1) O AVA como facilitador do processo de aprendizagem:

O e-mail me ajudou a lembrar os horários, trabalhos e "me evitou de ir" à faculdade à toa umas 4 ou 5 vezes.

2) Eficiência do professor em responder aos e-mails:

$\mathrm{O} e$-mail foi bem eficiente. Eu recebia a resposta bem rápido.

Alguns alunos relataram demora em receber respostas às mensagens enviadas. Por isso, foi preciso que o professor estabelecesse um critério para respondê-las. Vale destacar que a demora apontada pelos alunos não se deve a uma limitação da ferramenta, mas sim a uma falha na estratégia de administração do tempo do professor.

A respeito da "onipresença" do professor, o relato a seguir, retirado dos registros de $e$-mail, ilustra bem essa situação:

Boa tarde, professor!

Desculpa incomodá-lo no final de semana, mas é que estou com uma dúvida em relação àquele trabalho extra.

A caixa tem medida exata ou posso fazer do tamanho que eu quiser? E a caixa é com tampa, ou sem tampa? Posso fazer a caixa de qualquer forma geométrica, ou alguma específica?!

Abraços e bom final de semana!

Isabela, como vai?

$\mathrm{Na}$ Internet eu estou SEMPRE à disposição para tirar qualquer dúvida, com prazer!

Eu só peço que da próxima vez você use a ferramenta "tiradúvidas" da Sala de Aula Online, pois a sua dúvida pode ser a mesma de outros colegas.

Sobre a caixa, ela pode ser de qualquer tamanho e forma, pode ter tampa ou não e preferencialmente ser feita com material reciclado.

A entrega deverá ser feita na próxima aula, que será sexta-feira, dia 19.

Tenha um bom dia, Professor Alvaro.

Sobre o fato de o professor estar "SEMPRE à disposição", Paloff e Pratt (2004) sugerem a criação de uma estrutura na sala online, em que o professor possa: 
- criar horários específicos para o envio de mensagens;

- ser claro quanto ao número de respostas semanais às mensagens, quanto à natureza das mensagens, explicitando o que constitui uma mensagem substancial, e quanto às expectativas do curso;

- ficar atento à participação dos alunos e acompanhar qualquer mudança.

Outro comentário, que surgiu espontaneamente em uma conversa de chat, complementa essa questão:

É como se o professor estivesse 24 horas presente.

30 horas... 24 horas na Internet e 6 na faculdade... quase um Unibanco... hehehehehehehehh.

Pelo fato de a sala online estar aberta 24 horas por dia durante os sete dias da semana, Paloff \& Pratt (2004) sugerem que seja incluído um tempo para descanso, tanto para o professor quanto para os alunos, a fim de evitar a "sobrecarga".

\section{Chat}

A ferramenta chat permite:

- selecionar o chat da turma, o do curso ou, ainda, a função "conversa reservada", em que um participante pode se dirigir a outro em particular, sem ser visto pelo restante do grupo;

- ter acesso ao histórico das conversas realizadas pelo grupo (figura 3).

Figura 3 - Interface da ferramenta chat

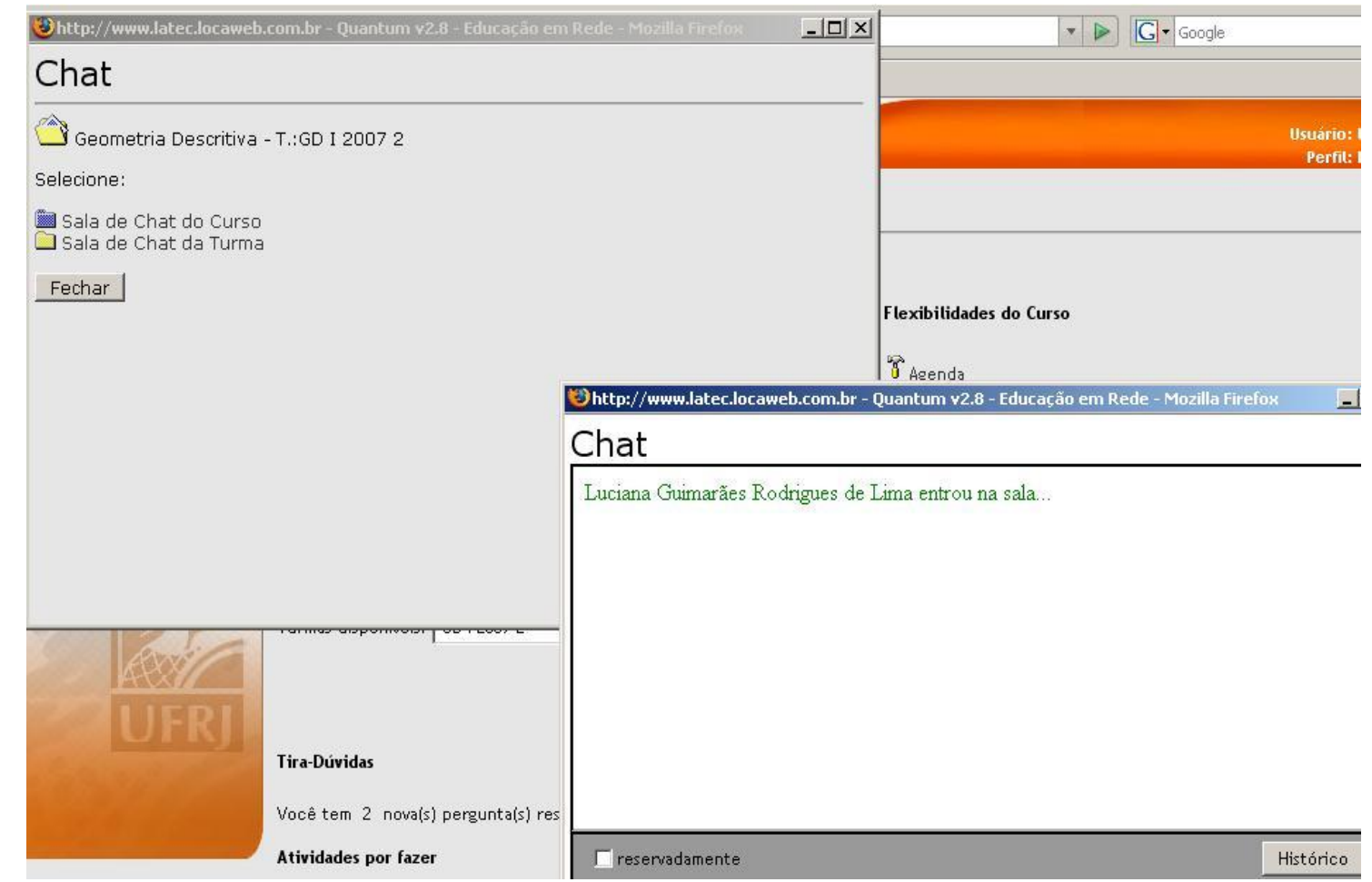

Fonte: Elaboração própria. 
Por meio do conteúdo dos chats, procurou-se verificar as possibilidades e os limites dos recursos de comunicação síncrona como mediadores de uma relação pedagógica entre aluno e professor, que estimulassem a reflexão, argumentação, análise e troca de experiências entre os participantes, bem como a busca de solução dos problemas, enfim, a construção do conhecimento e reestruturação de suas concepções do processo de ensino-aprendizagem.

A perspectiva dos participantes foi privilegiada. Abordaram-se assuntos que surgiram espontaneamente durante a discussão, tornando-a mais rica e produtiva.

Nos comentários abaixo, observa-se que foram mantidos os comportamentos do ensino centralizado no professor, por meio da hierarquização de saber:

Gnt tah bom NE... agora o professor entrou e a turma fica quieta.

Bom dia!!! Chegou o mestre!

A partir dos comentários realizados pelos alunos em questionários, foi possível verificar suas impressões quanto à praticidade na comunicação e facilidade do processo de aprendizagem nos chats:

Muito bom o chat, é um ótimo meio pra discutir qualquer assunto. $\mathrm{O}$ único problema, comentado por praticamente todos os presentes, foi a demora nas mensagens, que só apareciam após algum tempo, mas não atrapalhou muito.

É uma ferramenta que poderia ser mais utilizada.

É um bom modo de interação, e todos podem ver as dúvidas dos outros e entender um pouco melhor a matéria com as explicações.

O chat poderia acontecer mais vezes... é bem esclarecedor.

Caso eu queira falar sobre uma questão específica, é melhor o chat em q vc debate sobre o assunto. Já uma mensagem de $e$ mail nem sempre terá a resposta que vc espera. Num chat vc pode conduzir até suprir a dúvida.

Eu acho o chat uma ótima ferramenta para tirar dúvidas online.

Tem coisas que não dá para se tirar dúvida na aula.

Problemas como falta de esclarecimento de horário e data para utilização da ferramenta, bem como horário desencontrado com os outros alunos, foram as maiores 
dificuldades encontradas. Os comentários a seguir, retirados do histórico do chat, ilustram bem essa questão:

Eu gosto do chat pq acho que é a melhor maneira para tirar dúvida, entretanto, pro chat funcionar, é necessário marcar hora.

Geometria descritiva é uma matéria extremamente difícil de se expressar verbalmente! Mal consigo me expressar falando, quem dirá escrevendo. Seria interessante se houvesse a possibilidade de desenhar no chat, como é no msn, não sei se seria possível... mas chat escrito, pra mim, é inútil. Se tiver alguma dúvida, prefiro mandar por e-mail, ao professor.

Não, nunca entrei nesse chat daqui.

Nesses do site, eu já entrei, mas não tinha ninguém.

É... uma vez eu entrei, mas nem testei, pq estava vazia a sala...

Oi, Camila!!!! Tá difícil da gente se esbarrar nesse chat, kkkkk

Eu estava sozinha no chat... foi um bom momento para refletir!

O difícil é conseguir marcar com alguém, pois quase ninguém entra no chat e os horários da maioria dos alunos não coincidem.

Conclui-se para o uso do chat com fins educacionais, é preciso determinar um mediador para organizar as perguntas e os comentários, definir horários e limitar o número de participantes.

\section{Fórum}

A figura 4 mostra a interface da ferramenta fórum, onde se destaca, à esquerda da tela, a região de seleção do fórum desejado entre os fóruns propostos para a turma, cada um com uma proposta de discussão diferenciada. Pode-se ver ainda, na metade direita da tela, o espaço reservado para a discussão: proposição, réplica e tréplica. 


\section{Figura 4 - Interface da ferramenta fórum}

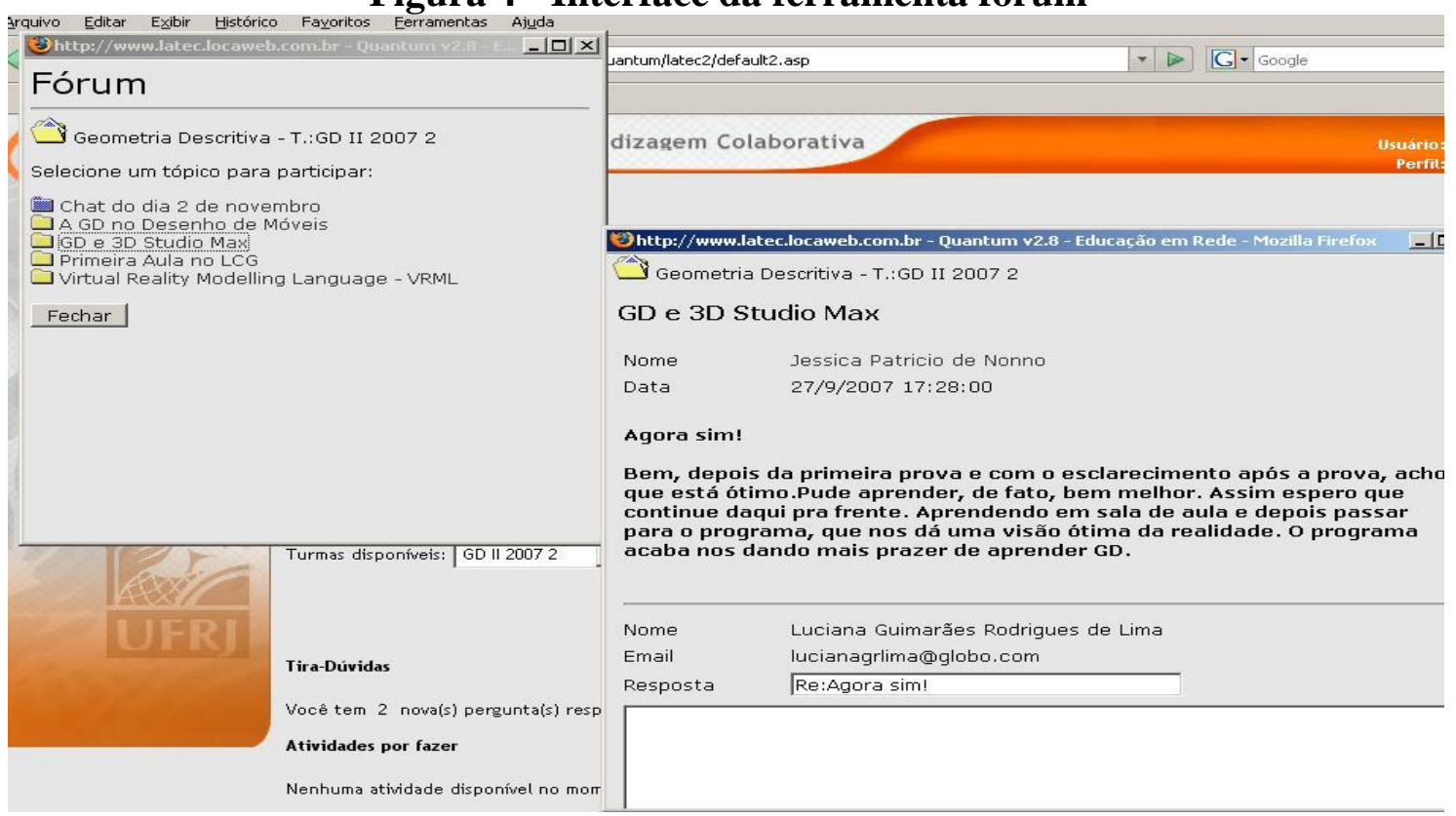

Fonte: Elaboração própria.

Durante a pesquisa foram analisadas várias proposições de discussão postadas pelo professor. A partir da análise das opiniões dos alunos, o professor procurou definir as melhores estratégias para a aprendizagem da disciplina.

O comentário a seguir, retirado do histórico do chat, indica a facilidade da ferramenta fórum no processo de aprendizagem:

$\mathrm{Eu}$ procurava nos fóruns para ver se alguém já tinha tido a mesma dúvida...senão, eu perguntava ao Alvaro.

Sobre o uso colaborativo da ferramenta, houve a intenção de que todos os participantes tivessem acesso à informação:

O bom é que no fórum, é que às vezes a gente tinha a dúvida que outra pessoa já havia perguntado. Melhor que no $e$-mail, que é "escondido".

$\mathrm{Na}$ conversa a seguir, ficou evidenciada uma tentativa de aproveitamento maior na utilização da ferramenta, no que diz respeito aos comentários, mesmo que simples, sobre a colaboração anterior da colega:

Pra ajudar os alunos de interiores que vão fazer uma cena (de interior ou exterior) no trabalho final um site bem legal $\mathrm{q}$ disponibiliza texturas, plug-ins, tutoriais e mais $\mathrm{mt}$ de coisas para o 3D max: http://www.tresd1.com.br/portal.php

Vai ser bem útil. Um abraço. 
Re:Re:Re: ?

Valeu, ingrid... vou ver o site agora ainda...

Re:Re:Re:Re: ?

Também vou dar uma conferida...

Apesar de o professor explicar aos alunos como seria o uso da ferramenta, percebe-se que ela foi subutilizada, vista como simples tira-dúvidas, como se observa na citação abaixo:

Cada aluno deve postar e também comentar sobre o trabalho do colega, dando sugestões enriquecedoras. Professor Alvaro

No fórum, o aluno deve postar a sua atividade e voltar em outros momentos para discutir as contribuições postadas pelos colegas. Quando esse retorno não ocorre, a interação é prejudicada. Como nos sugere o texto a seguir:

Mais do que na educação presencial, a interação entre professores e alunos na educação a distância é relevante para a manutenção do interesse dos alunos. $\mathrm{O}$ fórum por si mesmo não promove a interação. Essa só pode ser efetivada a partir da intencionalidade dos professores e alunos associada a um objetivo maior que é o alcance do conhecimento (BATISTA; GOBARA, 2007, p.3).

Assim, verificou-se na pesquisa que os tópicos postados consistiam de perguntas e respostas direcionadas ao professor, não havendo preocupação em responder aos comentários dos colegas. O fórum é potencialmente um recurso que permite o maior grau de interação entre os participantes em relação ao e-mail e o chat. Entretanto, o que se vê na prática é o despreparo e a falta de hábito em relação à utilização desse tipo de recurso para fins educacionais.

\section{Considerações finais}

A observação dos registros das ferramentas do ambiente virtual de aprendizagem permitiu verificar a percepção dos alunos quanto à sua utilização.

As conversas via e-mail possibilitaram que o olhar individual dos participantes fosse considerado. No entanto, tornou-se clara a necessidade de se estabelecerem critérios de envio de respostas às mensagens, de forma a propiciar uma melhor administração do tempo do professor, conferindo limites ao processo de comunicação e evitando o surgimento de expectativas não atendidas. 
É possível perceber que a ferramenta chat apresentou como ponto positivo o fato de proporcionar o encontro de alunos da mesma turma ou de turmas diferentes, aproximando-os na troca de ideias sobre a disciplina. Faz-se necessário, porém ressaltar seus limites em torno da determinação dos dias e horários para a realização dos encontros, de forma a evitar a frustração, apontada por alguns alunos, de se encontrarem sozinhos no chat.

Apesar da maioria dos alunos ainda não estar familiarizada com a ferramenta fórum, resultando na subutilização dos seus recursos para a realização de discussões via Internet, a detecção desse fato, proporcionada pela pesquisa, contribuiu para que o professor pudesse aperfeiçoar as estratégias de utilização dessa ferramenta.

A análise dos dados indicou que o ambiente virtual de aprendizagem mostrou-se muito útil no apoio ao ensino presencial, criando novas possibilidades educativas e mantendo um canal aberto para a comunicação e interação entre alunos e professor. A partir da observação do comportamento dos alunos nos encontros presenciais, comparando-o com aquele apresentado no ambiente virtual, pode-se constatar que os alunos mais tímidos e também os menos organizados foram beneficiados com o uso do AVA.

Com base nas entrevistas realizadas e nos depoimentos dos alunos, fica clara a percepção geral de que houve ganho significativo de qualidade, em relação ao ensino puramente presencial. Essa percepção reforça o senso comum de que existe a necessidade de articular o processo de ensino-aprendizagem às potencialidades tecnológicas, incorporando as transformações necessárias às demandas sociais e profissionais do mundo atual. 


\section{STUDENTS PERSPECTIVE OF A UNIVERSITY COURSE ON THE USE OF TOOLS EMAIL, CHAT AND FORUM IN A VIRTUAL LEARNING ENVIRONMENT}

ABSTRACT: This paper presents the results of a master thesis entitled "Communication, Interaction and Discourse in Virtual Learning Environments", developed by the Interdisciplinary Program of Applied Linguistics at the Federal University of Rio de Janeiro. The study aimed to investigate the possibilities offered by new information technologies and was developed based on data collected through questionnaires, interviews and observation of the virtual learning environment. The analysis focused on the moments of communication among agents in the Online Classroom of the GD Space Portal (Portal Espaço GD), considering the dialogues that take place in the e-mail, chat and forum tools. Comments made by questionnaires, and spontaneously made by students in the records of e-mails, chats and forums have been analyzed in such a way to identify as meaning nuclei related to students' perceptions of AVA.

KEYWORDS: Virtual learning environments. Discourse analysis. Semi-distance education.

\section{REFERÊNCIAS}

BELLONI, M. L. Mediatização: os desafios das novas tecnologias de informação e comunicação. In: BELLONI, M. L. Educação a distância. Campinas: Autores Associados, 1999. p.53-77.

COSTA, C. et al. Parâmetros para análise das ferramentas de aprendizagem colaborativa na internet. In: VIRTUAL EDUCA, 2006, Bilbao. Anais... Cidade do México: Virtual Educa, 2006. p.1-19.

BATISTA, E. M.; GOBARA, S. T. O fórum on-line e a interação em um curso a distância. RENOTE: Revista Novas Tecnologias na Educação, Porto Alegre, p.01-10, 01 dez. 2007. Disponível em: <www.cinted.ufrgs.br/ciclo9/artigos/8cErlinda.pdf>. Acesso em: 25 maio 2009.

FRANCO, M. A. S. Pedagogia da pesquisa-ação. Educação e Pesquisa, São Paulo, v.31, n.3, p.483-502, set./dez.2005. Disponível em:

<http://www.scielo.br/pdf/ep/v31n3/a11v31n3.pdf>. Acesso em: 17 jan. 2009.

LIMA, L. G. R. de.Comunicação, interação e discurso em ambientes virtuais de aprendizagem. 2009. 182f. Dissertação (Mestrado em Linguística Aplicada) Universidade Federal do Rio de Janeiro, Rio de Janeiro, 2009.

MARCUSCHI, L. A. Gêneros virtuais emergentes no contexto da tecnologia digital. In: MARCUSCHI, L. A.; XAVIER, A. C. dos S. (Org.). Hipertexto e gêneros digitais: novas formas de construção do sentido. Rio de Janeiro: Lucerna, 2005. p.13-67. 
PAIVA, V. L. M. de O. E-mail: um novo gênero textual. In: MARCUSCHI, L. A.; XAVIER, A. C. (Org.). Hipertextos e gêneros digitais. Rio de Janeiro: Lucerna, 2004, p.68-90.

PALLOFF, R. M.; PRATT, K. O aluno virtual: um guia para trabalhar com estudantes on-line. Porto Alegre: Artmed, 2004.

PIMENTA, S. G. Pesquisa-ação crítico colaborativa: construindo seu significado a partir de experiências com formação docente. Educação e Pesquisa, São Paulo, v.31, n.3, p.521-539, set./dez. 2005. Disponível em: <http://www.scielo.br/pdf/ep/v31n3/a13v31n3.pdf>. Acesso em: 15 jan. 2009.

PRIMO, A. F. T. Ferramentas de interação na web: travestindo o ensino tradicional ou potencializando a educação através da cooperação?. In: CONGRESSO IBEROAMERICANO DE INFORMÁTICA EDUCATIVA, 5., 2000, Viña del Mar. Papers... [S.1.]: RIBIE, 2000. Disponível em: <http://lsm.dei.uc.pt/ribie/docfiles/txt200372912647Ferramentas\%20de\%20intera\%C3 \%A7\%C3\%A3o\%20na\%20web.pdf>. Acesso em: 25 maio 2009.

THIOLLENT, M. Metodologia da pesquisa-ação. São Paulo: Cortez, 1994.

VAZ, M. F. R. Os padrões internacionais para a construção de material educativo online. In: LITTO, F. M.; FORMIGA, M. M. M. (Org.). Educação a distância: o estado da arte. São Paulo: Pearson, 2009. p.386-394. 